\title{
Avaliação das perspectivas de tratamento de esgotos no âmbito de uma bacia hidrográfica a partir do emprego de modelo matemático de qualidade de água - Estudo de caso da bacia do rio Muqui do Norte (Espírito Santo, Brasil)
}

\author{
Evaluation of wastewater treatment inside a watershed with water quality mathematical model - \\ Case study of the Muqui do Norte river watershed (Espírito Santo, Brazil) \\ Evaluación de las perspectivas de tratamiento de aguas residuales en una cuenca hidrográfica a \\ partir de modelo matemático de calidad del agua - Estudio de caso de la cuenca del río Muqui do
} Norte (Espírito Santo, Brasil)

Erika Hemerly Scandian ORCID: https://orcid.org/0000-0001-7267-1426 Universidade Federal do Espírito Santo, Brasil E-mail: erikahemerly@gmail.com

Carlos Henrique Juvenal Scalzer ORCID: https://orcid.org/0000-0002-4576-5424 Universidade Federal do Espírito Santo, Brasil E-mail: scalzercarlos@gmail.com José Antonio Tosta dos Reis ORCID: https://orcid.org/0000-0001-9916-1469 Universidade Federal do Espírito Santo, Brasil E-mail: jatreis@gmail.com

Antônio Sérgio Ferreira Mendonça ORCID: https://orcid.org/0000-0003-4273-0266 Universidade Federal do Espírito Santo, Brasil E-mail: anserfm@terra.com.br

Fernando das Graças Braga da Silva ORCID: https://orcid.org/0000-0002-3803-2257 Universidade Federal de Itajubá, Brasil E-mail: ffbraga.silva@gmail.com

\begin{abstract}
Resumo
Este trabalho teve como principal finalidade avaliar as perspectivas de tratamento de esgotos no âmbito da bacia hidrográfica do rio Muqui do Norte (Espírito Santo, Brasil), a partir do emprego de modelo matemático de qualidade de água. Para a modelagem dos cursos d'água da área de estudo foi utilizado o modelo QUAL-UFMG. A caracterização fisiográfica, avaliação da disponibilidade hídrica e das condições de produção e tratamento de esgotos na bacia hidrográfica do rio Muqui do Norte precederam à modelagem da qualidade de água. Foram modelados dois cenários de disposição final de efluentes: a) lançamento de esgoto no curso d'água sem tratamento; b) disposição final de efluentes com tratamento previsto nos planos municipais de saneamento das cidades que o rio atravessa - Muqui e Atílio Vivácqua. Os resultados indicaram que os padrões de qualidade estabelecidos para o Oxigênio Dissolvido (OD) e Demanda Bioquímica de Oxigênio não são atendidos em toda a extensão do rio Muqui, se considerada a disposição de esgotos brutos. Indicaram, adicionalmente, que a adoção tratamentos sugeridos pelos planos municipais de saneamento de Muqui e Atílio Vivácqua não permitiria ao atendimento do padrão para o OD apenas nos últimos cinco quilômetros do trecho simulado. Para que o padrão associado ao OD fosse atendido em toda a extensão do rio Muqui do Norte, a eficiência de remoção de DBO nas estações do município de Atílio Vivácqua deveria ser elevada para um mínimo de $70 \%$.
\end{abstract}

Palavras-chave: Modelo de qualidade de água; Simulação computacional; Tratamento de esgotos.

\footnotetext{
Abstract

The main purpose of this work was to evaluate, with a mathematical model of water quality, the perspectives of wastewater treatment in the Muqui do Norte river watershed (Espírito Santo, Brasil). The QUAL-UFMG model was used to model the watercourses in the study area. The physiographic characterization, evaluation of water availability and the conditions of production and treatment of wastewater in Muqui do Norte river watershed preceded the water quality modeling. Two scenarios for disposal of effluents were modeled: a) final disposal of raw sewage; b) final
} 
disposal of effluents with treatment provided for in the municipal sanitation plans for the cities of Muqui and Atílio Vivácqua. The results indicated that the quality standards for Dissolved Oxygen and Biochemical Oxygen Demand are not met along in the Muqui River, considering the final disposal of raw sewage. They also indicated that the adoption of treatments suggested by the municipal sanitation plans of Muqui and Atílio Vivácqua would not allow to respect the OD standard in the last five kilometers of the simulated stretch. To attend the standard for OD in the Muqui do Norte River, the BOD efficiency removal at the stations in the municipality of Atílio Vivácqua must be raised to a minimum of $70 \%$.

Keywords: Water quality model; Computer simulation; Wastewater treatment.

\section{Resumen}

El objetivo principal de este trabajo fue evaluar las perspectivas de tratamiento de aguas residuales en el ámbito de la cuenca del río Muqui do Norte (Espírito Santo, Brasil), utilizando un modelo matemático de calidad del agua. Para modelar los cursos de agua en el área de estudio se utilizó el modelo QUAL-UFMG. La caracterización fisiográfica, la evaluación de la disponibilidad de agua y las condiciones de producción y tratamiento de las aguas residuales en la cuenca del río Muqui do Norte precedieron a la modelización de la calidad del agua. Se modelaron dos escenarios para la disposición final de efluentes: a) descarga de aguas residuales al curso de agua sin tratamiento; b) disposición final de efluentes con tratamiento previsto en los planes de saneamiento municipal en los municipios de Muqui y Atílio Vivácqua. Los resultados indicaron que los estándares de calidad establecidos para el Oxígeno Disuelto (OD) y la Demanda Bioquímica de Oxígeno no se cumplen en toda la extensión del Río Muqui, considerando la disposición de las aguas residuales sin tratamiento. Asimismo, indicaron que la adopción de tratamientos sugeridos por los planes de saneamiento municipales de Muqui y Atílio Vivácqua no permitiría cumplir con la norma de OD solo en los últimos cinco kilómetros del tramo simulado. Para que el estándar asociado a la DO se cumpla en toda la extensión del río Muqui do Norte, la eficiencia de remoción de DBO en las estaciones del municipio de Atílio Vivácqua debe elevarse a un mínimo de $70 \%$.

Palabras clave: Modelo de calidad del agua; Simulación computacional; Tratamiento de aguas residuales.

\section{Introdução}

$\mathrm{O}$ acelerado crescimento populacional e o aumento na geração de resíduos têm produzido substancial aumento na demanda de água e comprometido a integridade dos corpos d'água em diferentes regiões do Brasil. Segundo Benassi (2002), o acelerado crescimento urbano e industrial está entre os fatores que mais severamente têm reduzido a disponibilidade hídrica, tanto pelo aumento no consumo de água, quanto pela perda da qualidade dos corpos d'água em decorrência do lançamento indiscriminado de efluentes brutos ou precariamente tratados.

$\mathrm{O}$ entendimento e a quantificação do fenômeno de autodepuração podem permitir a avaliação da capacidade de assimilação dos rios e impedir o lançamento de despejos acima da capacidade de suporte dos cursos d'água. Até um determinado limite, os cursos d'água podem assimilar as cargas afluentes sem comprometimentos do ponto de vista ambiental. No entanto, esta capacidade, que de fato constitui um recurso natural, deve ser utilizada dentro de conservadores critérios técnicos e, eventualmente, como forma de complementação dos processos de tratamento de esgotos.

Os modelos matemáticos de qualidade de água são as ferramentas tecnológicas que possibilitam a descrição e quantificação do fenômeno de autodepuração, uma vez que permitem compreender o ambiente aquático e descrevê-lo de forma integrada a partir de associações entre as características físicas, químicas e biológicas dos corpos d'água (Chapra et al., 2012). Knapik et al. (2003) ressaltam que a modelagem matemática da qualidade de água consiste em representar, de maneira simplificada, distintos sistemas e interações que ocorrem no ambiente aquático por meio de hipóteses estabelecidas a respeito do comportamento e estrutura do meio físico. A modelagem matemática da qualidade de água é realizada a partir de dois componentes básicos: a) equações que representem o escoamento e b) equações de transporte e balanço de massa que expressem a variação da concentração do parâmetro de qualidade de água.

Reis et al. (2015) observam que, considerando-se a perspectiva de manutenção da qualidade da água dos rios brasileiros, a implantação de estações de tratamento de efluente constitui a principal medida estrutural de controle do país. O processo de seleção de plantas de tratamento de efluentes sanitários, quando observado do ponto de vista de uma bacia hidrográfica, é usualmente complexo, função dos múltiplos lançamentos, de diferentes cargas, em corpos d'água com 
diferentes capacidades de assimilação. Neste contexto, a avaliação da capacidade de autodepuração dos corpos d'água - tarefa que condiciona níveis mínimos de tratamento dos efluentes - constitui uma das mais usuais aplicações dos modelos de qualidade de água. Os trabalhos Mendonça (1992), Reis (1997), Gastaldini et al. (2002), Oppa (2007) e Guedes (2009) constituem exemplos da aplicação dos modelos matemáticos para avaliação da capacidade de autodepuração de rios.

Dentre os vários modelos matemáticos de qualidade água disponíveis para a simulação das condições de qualidade de rios, o modelo QUAL-UFMG têm sido recorrentemente empregado nas simulações das condições de qualidade dos cursos d'água brasileiros. O modelo QUAL-UFMG, desenvolvido para o ambiente computacional da planilha eletrônica Microsoft Excel, permite a simulação das concentrações de oxigênio dissolvido (OD), demanda bioquímica de oxigênio (DBO), fósforo total e suas frações, nitrogênio total e suas frações e coliformes termotolerantes. Guedes (2009), Mourão Júnior (2010), Salla et al. (2013), Filho \& Neto (2018) e Tonon (2014) constituem diferentes exemplos de aplicação do modelo QUAL-UFMG com o propósito de avaliar a capacidade de assimilação de cursos d'água sob diferentes condições aporte de poluentes.

Este trabalho tem como finalidade principal estudar, com auxílio do modelo QUAL-UFMG, o comportamento das condições de qualidade dos cursos d'água do rio Muqui do Norte (Espírito Santo, Brasil), considerados diferentes perspectivas de disposição final de efluentes líquidos. Função das características da área de estudo, as simulações de qualidade de água estarão associadas à disposição final de efluentes domésticos.

\section{Metodologia}

\section{1 Área de Estudo}

A bacia hidrográfica do rio Muqui do Norte (Figura 1), área de estudo do presente trabalho, é afluente do Rio Itapemirim, um importante sistema hídrico da porção sul do estado do Espírito Santo. O Rio Muqui do Norte tem sua nascente a uma altitude de 600 metros no município de Muqui. Em seu percurso, atravessa a zona urbana dos municípios de Muqui e de Atílio Vivácqua. Sua foz, no rio Itapemirim, localiza-se no município de Itapemirim.

Com extensão de aproximadamente $90 \mathrm{~km}$, o Rio Muqui do Norte possui bacia com área de drenagem de $537 \mathrm{~km}^{2} \mathrm{e}$ possui 11 estações de tratamento de água que fazem captação na bacia do rio Muqui do Norte. De acordo com AGERH (2018), as indústrias das cidades de Muqui e Atílio Vivacqua (empresas de processamento de mármore e granito e abatedouro) são responsáveis pela captação de 12,4 L/s. O cultivo de café se apresenta como a maior atividade econômica da região, demandando aproximadamente $561 \mathrm{~L} / \mathrm{s}$ de água dos mananciais da bacia do rio Muqui do Norte. Os esgotos domésticos representam o maior aporte de efluentes aos cursos d'água da bacia hidrográfica do rio Muqui do Norte. 
Figura 1 - Mapa da bacia hidrográfica do rio Muqui do Norte.

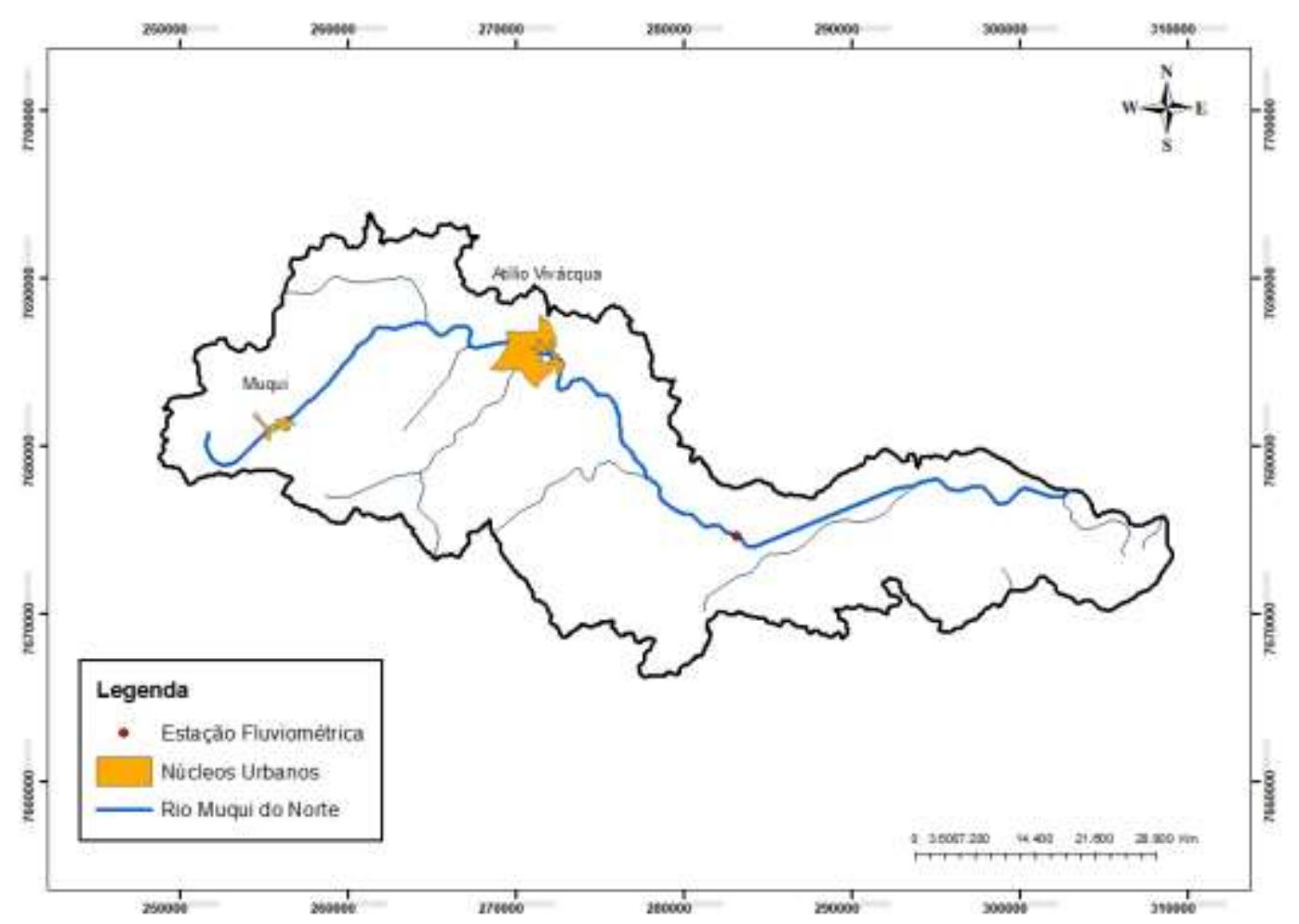

Fonte: Autores (2021).

\subsection{Caracterização fissiográfica e avaliação da disponibilidade hídrica}

As características fisiográficas, responsáveis por representarem aspectos como o relevo, a rede de drenagem, a cobertura vegetal, o uso e ocupação da superfície, dentre outros, foram extraídas de bases cartográficas digitais. Para a apropriação de variáveis fisiográficas foram manipulados, por meio de Sistema de Informações Geográficas, arquivos digitais contendo planos de informações (formato shapefile) disponíveis no Sistema Integrado de Bases Geoespaciais do estado do Espírito Santo (GEOBASES). Esta etapa do estudo permitiu a construção do diagrama unifilar da bacia hidrográfica do rio Muqui do Norte, a localização dos núcleos urbanos (associados aos lançamentos pontuais de esgotos) e a localização de estação fluviométrica instalada e em operação na bacia.

A função regional proposta por Piol (2017), estabelecida a partir do emprego do Método dos Valores Característicos (Equação 1), foi empregada para avaliação da disponibilidade hídrica dos corpos d'água da bacia hidrográfica do rio Muqui do Norte.

$$
\mathrm{Q}_{90}=0,0103 \cdot \mathrm{A}^{0,9316}
$$

Na equação 1, Q90 representa a vazão mínima com permanência de $90 \%\left(\mathrm{em} \mathrm{m}^{3} / \mathrm{s}\right)$ e A a área de drenagem $(\mathrm{km} 2)$. É relevante observar que a vazão $\mathrm{Q}_{90}$, por constituir vazão de referência para outorga pelo uso da água no estado do Espírito Santo, foi a vazão empregada para modelagem da qualidade da água.

Por meio do Sistema de Informações Hidrológicas (Hidroweb) da Agência Nacional de Águas (ANA) foram obtidos, adicionalmente, os registros de medições de descarga líquida da estação Fluviométrica Fazenda Cacheta, instalada e em operação na bacia hidrográfica do rio Muqui do Norte (estação fluviométrica indicada na Figura 1). A Tabela 1 apresenta as 
coordenadas geográficas, área de drenagem e valores médios de vazão, velocidade e profundidade registradas na Estação Fluviométrica Fazenda Cacheta.

Tabela 1 - Localização, área de drenagem e características hidrodinâmicas da estação fluviométrica Fazenda Cacheta.

\begin{tabular}{ccccccc}
\hline Estação & Latitude & Longitude & $\begin{array}{c}\text { Área de } \\
\text { Drenagem }\left(\mathbf{k m}^{2}\right)\end{array}$ & $\begin{array}{c}\text { Vazão } \\
\text { Média }\left(\mathbf{m}^{\mathbf{3}}\right)\end{array}$ & $\begin{array}{c}\text { Velocidade } \\
\text { média }(\mathbf{m} / \mathbf{s})\end{array}$ & $\begin{array}{c}\text { Profundidade } \\
\text { média }(\mathbf{m})\end{array}$ \\
\hline Fazenda Cacheta & $-21^{\circ} 02^{\prime}$ & $-41^{\circ} 09^{\prime}$ & 478,00 & 4,10 & 0,51 & 0,48 \\
\hline
\end{tabular}

Fonte: Autores (2021).

Os registros de medições de descarga permitiram a definição de relações funcionais entre variáveis hidrodinâmicas (vazão, velocidade e profundidade média) e a estimativa de constantes cinéticas, informações necessárias à condução da modelagem matemática da qualidade de água.

\subsection{Caracterização das condições de tratamento de esgotos no âmbito da bacia hidrográfica}

Para a descrição das condições de cobertura com o serviço de tratamento de esgotos dos municípios da bacia hidrográfica do rio Muqui do Norte foram inicialmente consultados os consultados os planos de saneamento básico dos municípios de Muqui e Atílio Vivácqua. De maneira complementar, foram consultadas informações reunidas no Atlas Esgotos - Despoluição de Bacias Hidrográfica, editado pela Agência Nacional de Águas (ANA, 2017) e no Sistema Nacional de Informações sobre Saneamento (BRASIL, 2018).

\subsection{Modelagem da Qualidade de Água}

Para simulação computacional da qualidade das águas do rio Muqui do Norte foi empregado o modelo QUALUFMG, modelo desenvolvido e detalhadamente apresentado por Von Sperling (2007).

Com auxílio do modelo QUAL-UFMG foram simulados os perfis de DBO e OD. Para simulação das concentrações de DBO foram considerados os fenômenos de desoxigenação associado à oxidação da matéria orgânica, não sendo consideradas as perdas de DBO associadas à sedimentação da matéria orgânica ou as contribuições referentes às cargas difusas internas de DBO (cargas que podem ser acrescidas ou suprimidas dos corpos d'água sem alteração da vazão, como a demanda bentônica). Para a simulação das concentrações de OD foram consideradas a reaeração atmosférica e a desoxigenação produzida pela oxidação da matéria orgânica. A simulação da variação temporal das concentrações de OD não incluiu as cargas difusas internas (fotossíntese, respiração e demanda bentônica) e o eventual consumo de oxigênio associado ao estabelecimento do ciclo do nitrogênio (consumo estabelecido pelo processo de conversão de amônia em nitrato).

No modelo QUAL-UFMG, as concentrações dos parâmetros de qualidade de água são calculadas por segmento do curso d'água, produzida a partir da soma da variação da concentração $(\mathrm{dC})$ no segmento com a concentração resultante do processo de mistura, conforme estabelecido pela equação 2.

$$
\mathrm{C}_{(\mathrm{i}+1)}=\mathrm{CM}_{(\mathrm{i})}+\mathrm{dC}_{(\mathrm{i})}
$$

$\mathrm{Na}$ equação 2, C representa a concentração final de um segmento do curso d'água (mg/L), CM a concentração de mistura no segmento $(\mathrm{mg} / \mathrm{L})$ e dC a variação da concentração no segmento $(\mathrm{mg} / \mathrm{L})$. As variações temporais das concentrações de DBO e déficit de OD no ambiente aquático são modeladas por meio de equações diferenciais ordinárias e de primeira 
ordem, conforme expressões 3 e 4 , respectivamente.

$$
\begin{aligned}
& \frac{d L}{d t}=-K_{d} \cdot L \\
& \frac{d D}{d t}=K_{d} \cdot L-K_{2} \cdot D
\end{aligned}
$$

Nas equações (3) e (4) $K_{d}$ representa o coeficiente cinético de decomposição da DBO no rio $\left(d^{-1}\right)$, L concentração remanescente de DBO (mg/L), $K_{2}$ o coeficiente cinético de reaeração $\left(\mathrm{d}^{-1}\right)$ e D o déficit de OD $(\mathrm{mg} / \mathrm{L})$.

Para a estimativa das constantes cinéticas que regulam os processos de reaeração atmosférica $\left(K_{2}\right)$ e desoxigenação $\left(\mathrm{K}_{\mathrm{d}}\right)$ foram empregadas fórmulas empíricas que associam as referidas constantes cinéticas com variáveis hidrodinâmicas dos corpos d'água, como as expressões reunidas em trabalhos como EPA (1985), Thomann \& Mueller (1987), Chapra (1997) e Von Sperling (2007).

Dois diferentes cenários foram considerados para as simulações de qualidade de água. Os cenários foram conformados da seguinte maneira:

- Cenário 1: disposição final dos efluentes brutos produzidos pelos municípios de Muqui e Atílio Vivácqua;

- Cenário 2: disposição final de efluentes submetidos aos níveis de tratamento correspondentes aos sistemas existentes ou projetados para os municípios de Muqui e Atílio Vivácqua, conforme planos de saneamento básico dos referidos municípios;

É relevante registrar que a bacia hidrográfica do rio Muqui do Norte não passou por um processo de enquadramento dos seus cursos d'água. Neste contexto, conforme estabelecido pela Resolução CONAMA nº 357/2005, todos os seus cursos d'água são classificados como classe 2. Este aspecto definiu os padrões ambientais considerados para a avaliação da evolução das condições de qualidade do rio Muqui do Norte.

\section{Resultados e Discussão}

\subsection{Caracterização fisiográfica, avaliação da geração de esgotos e apropriação de coeficientes cinéticos}

A caracterização fisiográfica permitiu a apropriação caracterização do sistema hídrico e a apropriação da altitude média (variável que condiciona a concentração de saturação de OD) e área de drenagem da bacia hidrográfica do rio Muqui do Norte. A Tabela 2 indica o comprimento do curso d'água principal, altitude média e área de drenagem da bacia associada ao exutório do trecho simulado.

Tabela 2 - Comprimento do rio principal, altitude média e área de drenagem da bacia hidrográfica do rio Muqui do Norte.

\begin{tabular}{cccc}
\hline Curso d'água & $\begin{array}{c}\text { Comprimento do curso d'água } \\
\text { principal }(\mathbf{k m})\end{array}$ & $\begin{array}{c}\text { Altitude média da bacia } \\
\text { hidrográfica }(\mathbf{m})\end{array}$ & $\begin{array}{c}\text { Área de drenagem da bacia } \\
\text { hidrográfica }\left(\mathbf{k m}^{\mathbf{2}}\right)\end{array}$ \\
\hline $\begin{array}{c}\text { Rio Muqui do } \\
\text { Norte }\end{array}$ & 90,0 & 215,1 & 537,0 \\
\hline
\end{tabular}

Fonte: Autores (2021).

Segundo população estimada pelo Instituto Brasileiro de Geografia e Estatística (IBGE) para o ano de 2020, as cidades de Atílio Vivácqua e Muqui possuem 12105 e 15526 habitantes, respectivamente. A estimativa do volume de efluentes domésticos por fonte/pessoa/dia para "Residências e Apartamentos", de acordo com a NBR 7229 (ABNT, 1993), é de 180 
L/pessoa.dia. A Tabela 3 indica a contribuição de esgotos estimada para os núcleos urbanos de Atílio Vivácqua e Muqui.

Tabela 3 - Contribuição de esgoto para os núcleos urbanos da bacia do rio Muqui do Norte.

\begin{tabular}{cccccc}
\hline Cidade & $\begin{array}{c}\text { População } \\
\text { (habitantes) }\end{array}$ & $\begin{array}{c}\text { DBO média esgoto } \\
\text { bruto }(\mathbf{m g} / \mathbf{L})\end{array}$ & $\begin{array}{c}\text { Volume de Efluente } \\
\text { Doméstico (L/pessoa.dia) })\end{array}$ & $\begin{array}{c}\text { Carga de esgoto } \\
(\mathbf{k g} / \mathbf{d i a})\end{array}$ & $\begin{array}{c}\text { Contribuição } \\
\left(\mathbf{m}^{\mathbf{3}} / \mathbf{s}\right)\end{array}$ \\
\hline $\begin{array}{c}\text { Atílio } \\
\text { Vivácqua }\end{array}$ & 12105 & 300 & 180 & 648 & 0,025 \\
\hline Muqui & 15526 & 300 & 180 & 829 & 0,032 \\
\hline
\end{tabular}

Fonte: Autores (2021).

A partir de um modelo exponencial, foram estabelecidas relações funcionais entre os registros de vazão (Q, em m3/s), velocidade $(\mathrm{V}$, em $\mathrm{m} / \mathrm{s})$ e profundidade $(\mathrm{H}, \mathrm{em} \mathrm{m})$ registrados na estação fluviométrica de Fazenda Cacheta, instalada e em operação na bacia (equações 5 e 6). Estas relações permitiram a estimativa das constantes cinéticas de reaeração atmosférica e desoxigenação (coeficientes necessários ao traçado dos perfis de OD e DBO com auxílio do modelo QUAL-UFMG).

$$
\begin{aligned}
& \mathrm{V}=0,3736 \cdot \mathrm{Q}^{0,2925} \\
& \mathrm{H}=0,2713 \cdot \mathrm{Q}^{0,4892}
\end{aligned}
$$

As equações (7) e (8) foram estabelecidas para apropriação dos coeficientes cinéticos de reaeração $\left(\mathrm{K}_{2}\right)$ e desoxigenação $\left(K_{d}\right)$. A expressão sugerida para apropriação do coeficiente $K_{2}$ (equação 7 ) foi estabelecida a partir da manipulação da equação originalmente proposta por Owens et al. (1964). Já a expressão sugerida para apropriação do coeficiente $K_{d}$ (equação 8) foi estabelecida a partir da manipulação de equação apresentada por EPA (1985) e Thomann \& Mueller (1987), consideradas as profundidades dos cursos d'água.

$$
\begin{aligned}
& \mathrm{K} 2=0,5372 \cdot \mathrm{Q} 0,782 \\
& \mathrm{Kd}=0,3 \cdot(0,1084 \cdot \mathrm{Q} 0,489)-0,434
\end{aligned}
$$

\subsection{Caracterização das condições de tratamento de esgoto no âmbito da bacia hidrográfica}

O plano municipal de saneamento básico de Muqui (PMM, 2015) indica que a cidade não possui estação de tratamento de esgoto (ETE), despejando os esgotos do município de forma bruta no rio Muqui do Norte. O plano municipal de saneamento ainda registra que $95 \%$ da população do município vive majoritariamente no entorno do centro da cidade, o que, de acordo com o plano, indica o lançamento dos esgotos de forma concentrada.

O Plano de Saneamento Básico do município de Atílio Vivácqua (PMAV, 2018), por sua vez, informa que o município possui rede coletora com cobertura de $90 \%$ dos domicílios. Registra, adicionalmente, que existem três estações de tratamento (ETE Atilio Vivacqua, ETE Aparecida e ETE Muqui) na bacia hidrográfica rio Muqui do Norte. No entanto, indica que as referidas estações de tratamento encontram-se desativadas, condição que impõe a disposição final, na forma bruta, de todos os esgotos domésticos produzidos na bacia. Conforme indicado na Tabela 4, as ETE's Atilio Vivacqua e Aparecida utilizariam reatores do tipo UASB, com eficiência prevista de remoção de DBO de aproximadamente 67\%; a ETE Muqui, por sua vez, utilizaria a associação de reatores do tipo UASB com Biofiltro aerado submerso, com eficiência prevista de remoção 
de DBO em $90 \%$.

Informações reunidas no Atlas Esgotos - Despoluição de Bacias Hidrográfica Águas (ANA, 2017) e no Sistema Nacional de Informações sobre Saneamento (BRASIL, 2018) também indicam que não existirem estações de tratamento de esgotos (ETE) em operação nos municípios de Muqui e Atílio Vivácqua.

Tabela 4 - Estações de tratamento na bacia do rio Muqui do Norte.

\begin{tabular}{cccc}
\hline Nome da ETE & Tipo de tratamento & $\begin{array}{c}\text { Eficiência remoção de DBO em } \\
\text { \% }\end{array}$ & $\begin{array}{c}\text { QTD de Esgoto tratado em } \\
\mathbf{m}^{3} / \mathbf{d i a}\end{array}$ \\
\hline ETE Atílio Vivácqua & Reator UASB & 67,50 & 1555,2 \\
\hline ETE Aparecida & Reator UASB & 67,50 & 2488,3 (máxima) \\
\hline ETE Muqui & UASB + biofiltro aerado \\
& submerso & 90,00 & 2488,3 (máxima) \\
\hline
\end{tabular}

Fonte: Autores (2021).

\subsection{Aplicação no modelo matemático de qualidade de água QUAL-UFMG}

As figuras 2 e 3 apresentam os perfis de OD e DBO, respectivamente, estabelecidos a partir de simulação da disposição final de esgoto bruto (condição de disposição estabelecida pelo primeiro cenário de simulação). Nos referidos gráficos (e nos gráficos subsequentes apresentados ao longo da seção), a linha em vermelho indica os padrões de qualidade associados aos cursos d'água classe 2.

Figura 2 - Perfil de OD para o rio Muqui do Norte considerada condição de disposição final de esgotos estabelecida pelo primeiro cenário de simulação.

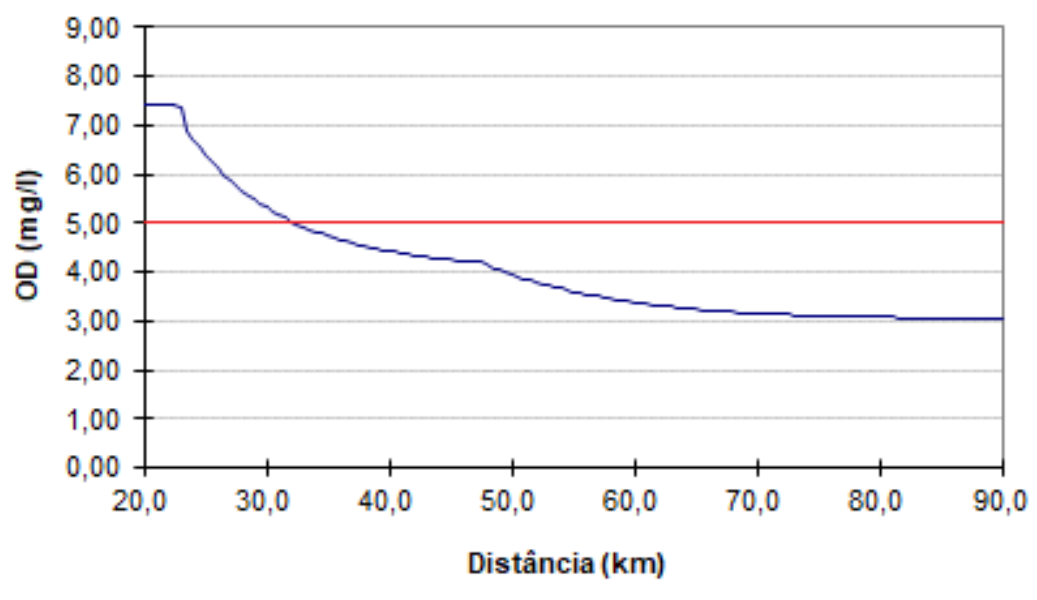

Fonte: Autores (2021). 
Figura 3 - Perfil de DBO para o Rio Muqui do Norte considerada condição de disposição final de esgotos estabelecida pelo primeiro cenário de simulação.

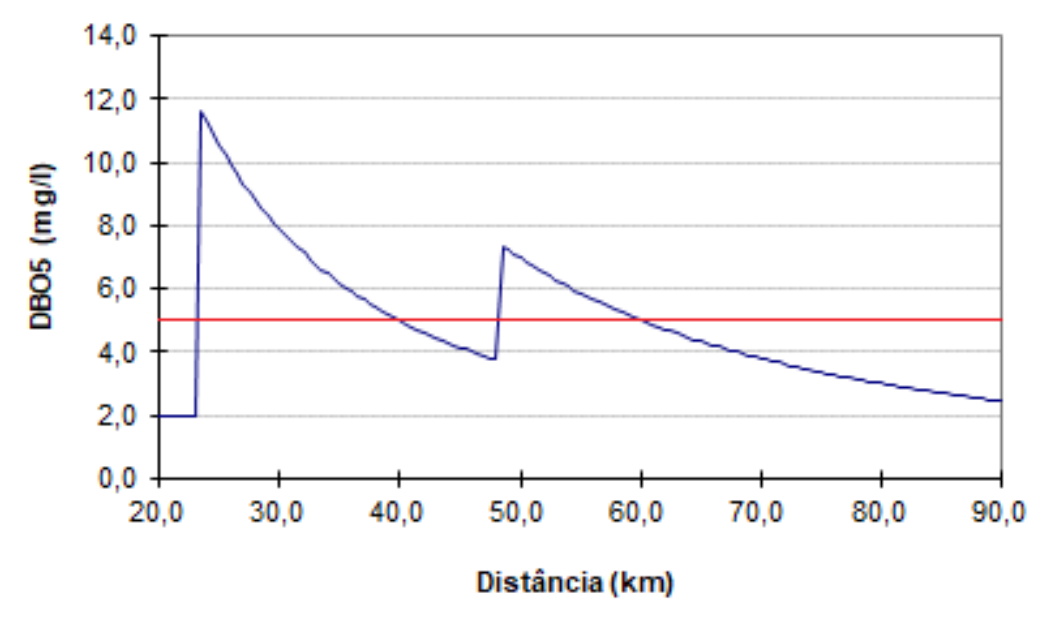

Fonte: Autores (2021).

Da simples inspeção dos referidos gráficos é possível observar que a disposição final dos esgotos brutos dos núcleos urbanos de Muqui e Atílio Vivácqua produz picos de concentração de DBO que superam o padrão de qualidade ambiental assumido como referência ( $5 \mathrm{mg} / \mathrm{L}$, correspondente ao padrão para rios classe 2). Como consequência, as concentrações de OD são severamente comprometidas ao longo do trecho simulado, apresentando-se abaixo do padrão de qualidade ambiental (5 $\mathrm{mg} / \mathrm{L}$ ) a partir do quilômetro 30, em seção situada aproximadamente $7 \mathrm{~km}$ a jusante do ponto de disposição final dos esgotos de Muqui.

O levantamento da cobertura do serviço de tratamento de esgotos nos municípios de Muqui e Atílio Vivácqua indicou não existirem estações de tratamento em operação na bacia do rio Muqui do Norte. No entanto, o Plano de Saneamento Básico do Município de Atílio Vivácqua indicou a existência de três estações de tratamento de esgotos na bacia (ETE's Atilio Vivacqua, Aparecida e Muqui, conforme Tabela 4) que ainda não operavam, quando da edição do referido plano (plano editado em 2018). Este contexto estabeleceu as condições de contorno que definiram o segundo cenário de simulações, no qual os esgotos produzidos pelo núcleo urbano de Muqui seriam submetidos a tratamento que permitiu a remoção de $90 \%$ da DBO, enquanto os esgotos de Atílio Vivácqua seriam submetidos a tratamento com remoção de DBO de aproximadamente $67 \%$. As figuras 4 e 5 apresentam os perfis de OD e DBO, respectivamente, estabelecidos a partir da incorporação dos sistemas de tratamento de esgotos propostos para os núcleos urbanos da bacia do rio Muqui do Norte. 
Figura 4 - Perfil de OD no Rio Muqui do Norte considerada condição de disposição final de esgotos estabelecida pelo segundo cenário de simulação.

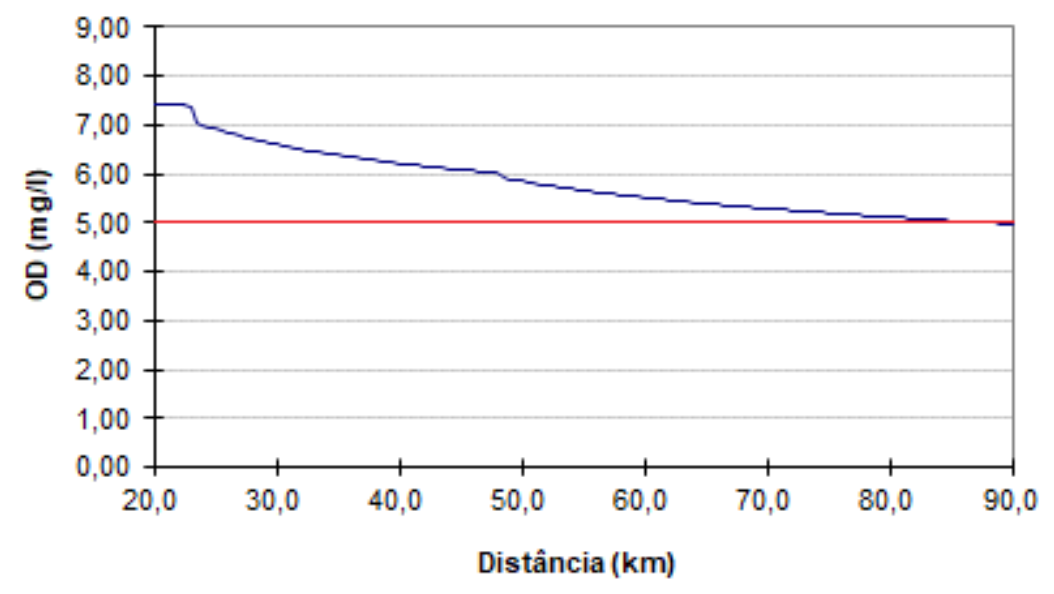

Fonte: Autores (2021).

Figura 5 - Perfil de DBO no Rio Muqui do Norte considerada condição de disposição final de esgotos estabelecida pelo segundo cenário de simulação.

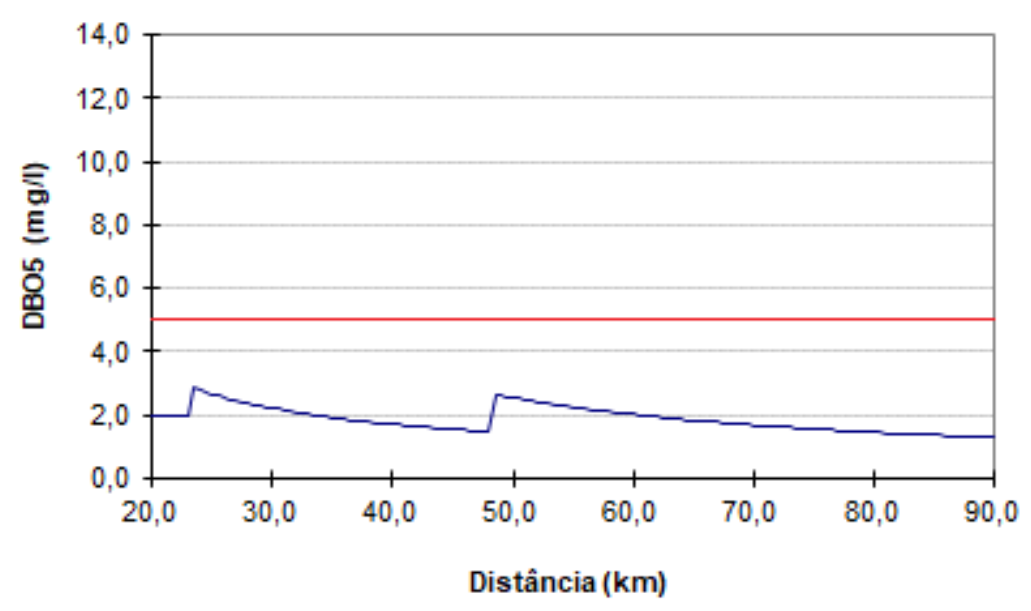

Fonte: Autores (2021).

Os perfis de OD (Figura 4) e DBO (Figura 5) indicam que os sistemas indicados no Plano de Saneamento Básico do Município de Atílio Vivácqua, se em operação, permitiriam melhorar substancialmente as condições de qualidade do rio Muqui do Norte. As simulações indicaram que as concentrações de DBO permaneceriam abaixo do limite imposto para cursos d'água classe $2(5 \mathrm{mg} / \mathrm{L})$ em toda a extensão simulada. As concentrações de OD, por sua vez, ficariam ligeiramente abaixo do padrão de qualidade ambiental $(5 \mathrm{mg} / \mathrm{L}$ para rios classe 2$)$ apenas nos últimos $5 \mathrm{~km}$ do trecho simulado.

Considerando-se a) que a estação de tratamento de esgotos proposta para o núcleo urbano de Muqui já apresentaria, a princípio, elevada eficiência de remoção de DBO (remoção sugerida de 90\%) e b) que os padrões de OD não seriam atendidos apenas em pequena porção do trecho final simulado, a jusante do núcleo urbano de Atílio Vivácqua, simulações complementares indicaram que a manutenção da eficiência proposta para a ETE Muqui, com elevação da capacidade de redução da carga orgânica disposta pelo município de Atílio Vivácqua em aproximadamente 5\% (aumento das eficiências de remoção de DBO das ETE's do município de Atílio Vivácqua para 70\%), permitiria o atendimento dos padrões de qualidade para o OD ao longo de todo o trecho simulado. 
É relevante registrar que os resultados apresentados são, naturalmente, decorrentes das condições de contorno assumidas para a condução das simulações. Os coeficientes cinéticos de reaeração e desoxigenação, ainda que estimados por procedimento de condução expedita, conduziram a simulações de qualidade de água que indicaram severo comprometimento da qualidade da água do rio Muqui do Norte, quando da disposição final de esgotos brutos (primeiro cenário de simulação). Ainda que avaliações mais consistentes só possam ser estabelecidas a partir de trabalhos de calibração do modelo de qualidade de água, atividade que envolveria esforço sistemático de monitoramento dos efluentes e das condições hidrodinâmicas e dos parâmetros modelados no curso d'água, os perfis de OD e DBO produzidos com a disposição final dos esgotos brutos sugerem ser improvável o atendimento dos padrões de qualidade ambiental sem a implementação de sistemas de tratamento com os níveis de remoção de matéria orgânica similares àqueles considerados para a definição do segundo cenário de simulação.

\section{Conclusões e Recomendações}

A partir da condução do presente estudo, foram consideradas relevantes as seguintes conclusões:

- As simulações das condições de qualidade de água indicaram que os padrões de qualidade de água para OD e DBO não seriam atendidos em porções relevantes do rio Muqui do Norte com a disposição final dos esgotos brutos produzidos pelos núcleos urbanos dos municípios de Muqui e Atílio Vivácqua;

- Com a eventual implementação dos sistemas de tratamento de esgotos indicados pelo Plano de Saneamento Básico do Município de Atílio Vivácqua (reatores do tipo UASB com eficiência prevista de remoção de DBO de aproximadamente 67\% para o núcleo urbano de Atílio Vivácqua e associação de reatores do tipo UASB e Biofiltro aerado submerso com eficiência prevista de remoção de DBO em 90\% para Muqui), as concentrações de DBO atenderiam ao padrão de qualidade ambiental fixado para rios classe $2 \mathrm{em}$ toda a extensão do rio Muqui do Norte. $\mathrm{O}$ OD, no entanto, permaneceria abaixo do padrão de qualidade nos últimos 5 quilômetros do trecho simulado.

- Consideradas as condições de contorno assumidas para a condução das simulações de qualidade de água, o atendimento do padrão de qualidade ambiental fixado para o OD em toda a extensão do rio Muqui do Norte demandaria o aumento da eficiência de remoção de DBO nas estações associadas ao município de Atílio Vivácqua para aproximadamente $70 \%$.

Recomenda-se que o conjunto de simulações conduzidas neste trabalho seja objeto de revisão na medida em que seja possível a adequada calibração do modelo de qualidade de água (perspectiva possível após eventual implementação de consistente trabalho de monitoramento hidrodinâmico e qualidade de água na bacia do rio Muqui do Norte) e verificação das efetivas condições de tratamento de esgotos no âmbito da bacia hidrográfica.

\section{Referências}

ABNT - Associação Brasileira de Normas Técnicas (1993). NBR 7229: Projeto, construção e operação de sistemas de tanques sépticos. Rio de Janeiro, Associação Brasileira de Normas Técnicas.

AGERH - Agência Estadual de Recursos Hídricos. (2018) Diagnóstico e Prognóstico das Condições de Uso da Água da Bacia Hidrográfica do Rio Itapemirim - Relatório da Etapa A. Vitória, Agência Estadual de Recursos Hídricos.

ANA - Agência Nacional de Águas. (2017). Atlas esgotos: despoluição de bacias hidrográficas. Brasília, Agência Nacional de Águas - Secretaria Nacional de Saneamento Ambiental.

Benassi, S. F. (2002). Estudo das Variáveis Limnologias e do Processo de Autodepuração na Descontinuidade Serial do Ribeirão Bonito (SP). Doctoral dissertation, Escola de Engenharia de São Carlos - Universidade de São Paulo).

Chapra, S. C. (1997). Surface Water-Quality Modeling. Illinois, Waveland Press.

Chapra, S. C., Pelletier, G. \& Tao, H. (2012). QUAL2K: A Modeling Framework for Simulating River and Stream Water Quality (Version 2.12): Documentation and Users Manual. Medford, MA: Civil and Environmental Engineering Department - Tufts University. 
Research, Society and Development, v. 10, n. 12, e124101220221, 2021

(CC BY 4.0) | ISSN 2525-3409 | DOI: http://dx.doi.org/10.33448/rsd-v10i12.20221

EPA - United States Envirommental Protection Agency (1985). Rates, Constants and Kinetics Formulations in Surface Water Quality Modeling. Athens, United States Envirommental Protection Agency.

Filho, A. A. O. \& Neto, I. E. L. (2018). Modelagem da qualidade da água do rio Poti em Teresina (PI). Engenharia Sanitária e Ambiental, 23(1), 3-14.

Gastaldini, M., Seffrin, G. \& Paz, M. (2002). Diagnóstico Atual e Previsão Futura da Qualidade das Águas do Rio Ibicuí Utilizando o Modelo Qual2E. Engenharia Sanitária e Ambiental, 7(4), 129-138.

Guedes, H. A. L. (2009). Estudo Matemático-Experimental da Qualidade da Água e da Capacidade de Autodepuração do Rio Pomba. (Doctoral dissertation, Universidade Federal de Viçosa).

Knapik, H. G., Fernandes, S., C. V., Bassanesi, K. \& Porto, M. F. A. (2003). Qualidade da Água da Bacia do Rio Iguaçu: Diferenças Conceituais entre os Modelos QUAL2E e QUAL2K. Revista Brasileira de Recursos Hídricos, 16 (2), 75-88.

Mendonça, A. S. F. (1992). Apllication of the QUAL2E Model to Environmental Impact Assessment. Advances in Hydro Science and Engineering, 1(2), 339354.

Mourão Júnior, P. R. (2010). Aplicação do modelo de autodepuração de qualidade das águas QUAL-UFMG. (Doctoral dissertation, Universidade Federal do Espírito Santo).

Owens, M., Edwards, R.W. \& GIBBS, J.W. (1964). Some reaeration studies in stream. International Journal Air Water Pollution, 8/9(8), 469-486.

Piol, M. V. A. (2014). Análise regional de curvas de permanência e de curvas de probabilidade de vazóes mínimas - Avaliação do desempenho de diferentes métodos de regionalização. (Doctoral dissertation, Universidade Federal do Espírito Santo).

PMM - Prefeitura Municipal de Muqui. (2015). Plano Municipal de Saneamento Básico e Plano Municipal de Gestão Integrada de Resíduos Sólidos do Município de Muqui. Muqui, Prefeitura Municipal de Muqui.

PMAV - Prefeitura Municipal de Atílio Vivácqua. (2018). Plano Municipal de Saneamento Básico e Plano Municipal de Gestão Integrada de Resíduos Sólidos de Atílio Vivácqua - Relatório Final. Atílio Vivácqua, Prefeitura Municipal de Atílio Vivácqua - Fundação Nacional de Saneamento - Universidade Federal Fluminense.

Oppa, L. F. (2007). Utilização de modelo matemático de qualidade da água para análise de alternativas de enquadramento do Rio Vacacaí Mirim. (Doctoral dissertation, Universidade Federal de Santa Maria).

Reis, J. A. T. (1997). Estudo dos padrões para compostos amoniacais em efluentes e cursos d'água interiores (Doctoral dissertation, Universidade Federal do Espírito Santo).

Reis, J. A. T., Valory, J. L., Mendonça, A. S. F. (2015). Seleção de eficiências de tratamento de esgotos a partir da manutenção de equidade entre sistemas de tratamento - uma abordagem para o gerenciamento de bacias hidrográficas. Revista Brasileira de Recursos Hídricos, 20(4), 862-871.

Salla, M. R., Arquiola, J. P., Solera, A., Álvarez, J. A., Pereira, C. E., Filho, F. E. A. \& Oliveira, A. L (2013). Sistema de suporte à decisão em recursos hídricos na Bacia Hidrográfica do Rio Uberabinha, Minas Gerais. Revista Brasileira de Recursos Hídricos, 19(1), 189-204.

Thomann, R. V. \& Mueller, J. A. (1987). Principles of surface water quality modeling and control. New York, Harper e Row.

Tonon, K. (2014). Modelagem da Qualidade da Água utilizando os Modelos StreeterPhelps e QUAL-UFMG na Bacia do Rio Lambari - Poços de Caldas $(M G)$ (Doctoral dissertation, Universidade Federal Alfenas).

Von Sperling, M. (2007). Princípios do Tratamento Biológico de Águas Residuárias - Estudos e Modelagem da Qualidade da Água de Rios. Belo Horizonte, DESA - UFMG. 